\title{
Subtidal current structure and variability of the continental shelf and slope of the northern South China Sea
}

\author{
Jen-Hua Tai ${ }^{1,2, *}$, Kai-Chieh Yang ${ }^{2}$, and Glen Gawarkiewicz ${ }^{3}$ \\ ${ }^{1}$ Research Center for Environmental Changes, Academia Sinica, Taipei City, Taiwan \\ ${ }^{2}$ Institute of Oceanography, National Taiwan University, Taipei City, Taiwan \\ ${ }^{3}$ Woods Hole Oceanographic Institution, Woods Hole MA, USA
}

\begin{abstract}
Article history:
Received 14 July 2016

Revised 6 October 2016

Accepted 5 November 2016

Keywords:

Continental shelf currents, Continental slope currents, Ekman transport, Sea level gradient, Geostrophic current variations

Citation:

Tai, J.-H., K.-C. Yang, and G. Gawarkiewicz, 2017: Subtidal current structure and variability of the continental shelf and slope of the northern South China Sea. Terr. Atmos. Ocean. Sci., 28, 411-423, doi: 10.3319/TAO.2016.11.05.01
\end{abstract}

\begin{abstract}
The spatial structures and temporal variations in subtidal currents in the northern South China Sea (SCS) are quantified in this study using 20-day to 9-month measurements from eight acoustic Doppler current profiler moorings deployed on the shelf and slope. The moored observations demonstrated that subtidal currents varied considerably with no persistent current feature on the shelf or slope. In winter, transient northeastward subtidal flows appeared sporadically but only when the wind stress was lower than 1 dyne $\mathrm{cm}^{-2}$. The potential transient along-shelf flow formation mechanisms during winter are attributed to the variation in cross-shelf and alongshelf sea levels. The variation in cross-shelf sea level is due to Ekman transports varying over a period of $100 \mathrm{~h}$. The variation in cross-shelf sea level gradient induced by the wind generates an along-shelf geostrophic current. When the sea level gradient anomaly is negative (i.e., sea level anomaly increased seaward), a transient shelf current appears, whereas the opposite phenomenon occurs as the sea level anomaly decreases seaward. The variation in the along-shelf sea level is due to the along-shelf sea level setup or set down as a result of shelf water accumulation or reduction near Hainan Island over a period of approximately $400 \mathrm{~h}$. Other possible factors affecting subtidal currents include fresh water inputs from the Taiwan Strait, typhoons and eddies in the northern SCS.
\end{abstract}

\section{INTRODUCTION}

The South China Sea (SCS) is semi-enclosed and the largest marginal sea in the western Pacific Ocean. The SCS is encompassed by the Asian continent, the Philippines, Indonesia, and other islands. It contains inflows and outflows from adjacent seas through several channels. The largest channel is the Luzon Strait (Fig. 1), which connects the SCS and western Pacific Ocean and is considered the primary conduit for water exchange between these two water bodies. In the north, the SCS joins the East China Sea (ECS) through the Taiwan Strait (Wyrtki 1961).

A broad continental shelf and slope are found in the northern part of the SCS. The shelf, located off the southern coast of China, is generally shallower than $100 \mathrm{~m}$. It spans approximately $400 \mathrm{~km}$ from the coast to the continental slope and extends approximately $800 \mathrm{~km}$ from Hainan Is-

\footnotetext{
* Corresponding author

E-mail:jhtai@gate.sinica.edu.tw
}

land to the southern opening of the Taiwan Strait. The currents on the shelf are tightly coupled to the currents in the Taiwan Strait (Su and Wang 1987) and Luzon Strait.

The subtidal current on the shelf reflects seasonal variation corresponding to shifts in the Asian monsoon (e.g., Wyrtki 1961; Shaw and Chao 1994; Hu et al. 2000; Gan et al. 2009). In summer, when the southwest monsoon prevails, the current over the shelf flows to the northeast. This northeastward flow can transport shelf water masses, including discharge from the Pearl River, to the southern opening of the Taiwan Strait (Gan et al. 2009). A southwestward coastal current exists in the west of the Pearl River. This current diverges into two branches near Hainan Island, one of which enters the Qiongzhou Strait (between Hainan Island and mainland China) and the other flows southward along the Hainan Island Coast, forming a cyclonic circulation in the area (Bao et al. 2005). In winter, the northeast monsoon dominates, and the current over the shelf separates 
into three flow patterns (Guo et al. 1985). Over the inner shelf, the current flows southwestward (i.e., Guangdong coastal current) along the coast of China from the southern opening of the Taiwan Strait toward Hainan Island. Over the outer shelf, the current flows primarily toward the northeast and southwestward slope current.

In addition to the seasonal variations, a particular current on the shelf, the SCS Warm Current (SCSWC), identified by Guan (1978) through sparse hydrographic observations, has drawn the attention of oceanographers since the 1970s. The SCSWC is believed to dominate the shelf and shelf break and is a year-round, strong, narrow, northeastward current. It apparently flows against the wind during the winter monsoon season (Guan and Chen 1964; Guan 1978, 1985; Guo et al. 1985; Guan and Fang 2006). The SCSWC pathway is primarily over the shelf between the 100- and 400-m isobaths. The vertical extent of the SCSWC is from the surface to a depth of $300 \mathrm{~m}$. It likely originates in the vicinity of Hainan Island (Guan 1978, 1985). This pathway was described in detail by the SCS Branch (SCSB), State Oceanic Administration (SOA), in 1990 (SCSB 1990). The SCSWC is considered a source of the Taiwan Warm Current and could be a crucial pathway transporting waters from the SCS to the Taiwan Strait and even to the ECS (Su and Wang 1987).

The SCSWC formation mechanisms have been examined in numerical modeling studies since the 1990s. Chao et al. (1995) and Chiang et al. (2008) demonstrated that the SCSWC is caused by northeast monsoon relaxation during the winter months because of the pressure gradient relaxation between Hainan Island and the southern opening of the Taiwan Strait. The SCSWC does not exhibit a distinct pattern during summer monsoon relaxation. Hsueh and Zhong (2004) suggested that the pressure field caused by the Kuroshio intrusion is a crucial factor for SCSWC formation. The SCSWC is well developed over the shelf during summer but exists only near the shelf break during winter. Yang et al. (2008) concluded that the SCSWC is a source- and sinkdriven flow induced by the Taiwan Strait Current, which is a year-round northward flow through the Taiwan Strait.

Gawarkiewicz et al. (2004) analyzed the current velocity through 2 years of hydrographic surveys and observed that current structures across the shelf varied substantially in the study period. In April 2000, the current flowed northeastward along the isobaths, whereas in May 2001, the flow over the slope was southwestward. The authors suggested that the strong density contrast between the outer shelf and upper slope water masses is a factor driving the flow northeastward.

Previous studies demonstrated the shelf circulations in the northern SCS. However, most studies were based on short-term moored current observations or several one-time hydrographic surveys and could not clarify the intermittent low-frequency currents driving factor. During the past decade in situ current measurements in the northern SCS have increased significantly. In the present study, we examined the moored current measurements from numerous sources including moorings from the Asian Seas International Acoustics Experiment (ASIAEX) field observations. Although moored data from ASIAEX were primarily analyzed to identify nonlinear internal solitary waves (Lynch et al. 2004), these data also provide an opportunity to examine the lowfrequency variability of currents on the shelf and slope of the northern SCS. In addition to moored currents, satellite-based ocean surface wind, sea surface height anomaly (SSHA), in situ bottom pressure, and sea level data were used.

Our study extends previous investigations by quantifying the spatial structure and temporal variability of subtidal currents on the shelf and slope of the northern SCS and by investigating the possible mechanisms that cause variability in the currents. The remainder of this paper is organized as follows. We describe the fieldwork performed in this study

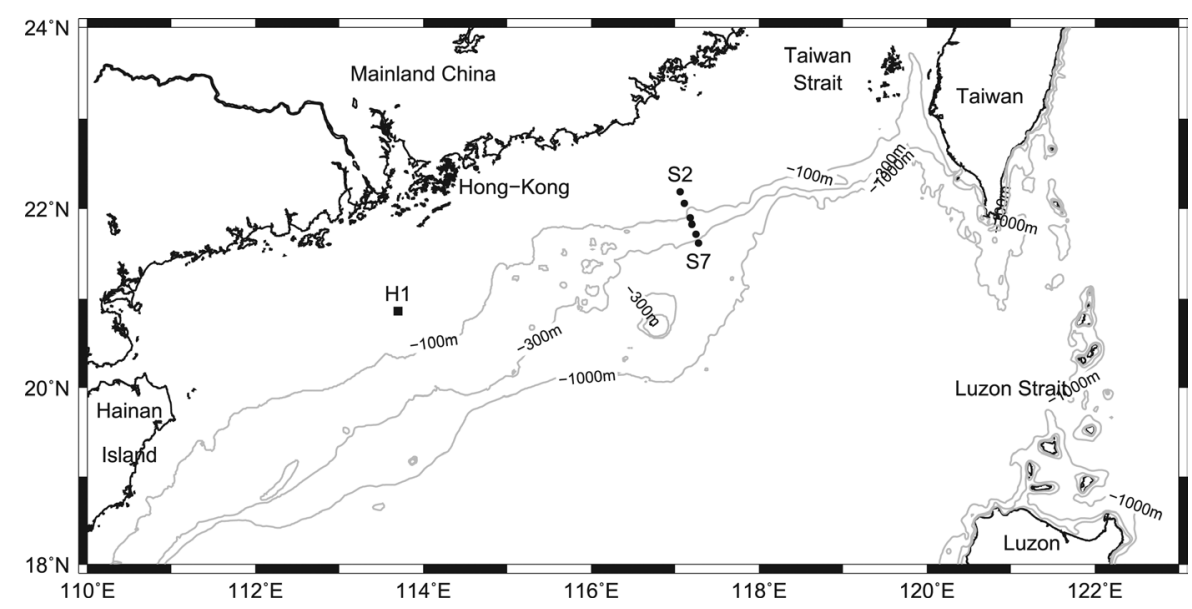

Fig. 1. Map of the northern SCS and mooring locations for this study. The contour lines denote the 100-, 300-, and 1000-m isobaths. The dots (stations S2 - S7) represent the mooring locations for the ASIAEX experiment in 2001. Stations S7 and H1 are long-term observation sites. 
in section 2. The spatial and temporal variability in currents on the continental shelf and slope are presented in section 3. In section 4 , we discuss the factors affecting current variability. Finally, conclusions are presented in section 5 .

\section{FIELDWORK}

Eight moorings instrumented with bottom-mounted acoustic Doppler current profilers (ADCPs) were deployed on the shelf and shelf break of the northern SCS (Fig. 1) under several international science programs, ASIAEX in 2001 and the Variations around the Northern SCS/Windy Islands Soliton Experiment (VANS/WISE) program in 2005 and 2006. The station names, mooring locations, local water depths, vertical bin sizes, record duration, and observation depth ranges are presented in Table 1. These ADCP moorings sampled current velocity at 1 - to 3-min intervals. Study data were averaged into 1-h intervals with a corresponding root-mean-square error of approximately $2 \mathrm{~cm} \mathrm{~s}^{-1}$. The vertical bin sizes varied from $4-10 \mathrm{~m}$.

Six of these eight moorings were deployed in a crossshelf mooring array (stations S2 - S7, denoted by filled circles in Fig. 1) extending from the inner shelf to the continental slope with the water depth increasing seaward from station S2 (approximately $70 \mathrm{~m}$ ) toward station S7 (approximately $350 \mathrm{~m}$ ) from April to May 2001. The data were examined by Beardsley et al. (2004), Duda et al. (2004), and many others studying barotropic and baroclinic tides as well as the characteristics of internal solitary waves. Moreover, the data facilitate the study of the spatial structure of subtidal currents on the shelf and shelf break.

Shelf current structure can be investigated using station H1, another bottom-mounted ADCP mooring on the shelf. Station H1 was located southwest of the ASIAEX array over the middle of the continental shelf. In addition to ADCP, H1 also carried a temperature and pressure gauge. The current velocity and temperature at station $\mathrm{H} 1$ was measured for the entire winter from 4 November 2001 to 21 March 2002. The long-term in situ observation of shelf currents in the northern SCS is valuable because of the difficulty in maintaining moorings in areas with intensive fishing activity and strong storms and currents. The extended deployment at station H1 is particularly valuable. Station S7 was later re-deployed at the slope for another 9 months from 29 April 2005 to 18 January 2006, providing another long-term velocity record at the slope.

The measurements from all eight moorings provided the most comprehensive results in the spatial (cross- and alongshelf) and temporal variability in currents in the northern SCS shelf region. These currents have not been well elucidated to date. We focused on subtidal currents in this study. The data presented here are 48-h low-pass-filtered.

Ocean surface wind data, extracted from the archive of the QuikSCAT satellite and the National Centers for Environmental Prediction (QSCAT/NCEP reanalysis) blended ocean wind, were used to interpret the forcing of the observed currents. The temporal and spatial resolutions are $6 \mathrm{~h}$ and a half-degree, respectively.

\section{RESULTS}

\subsection{Cross-Shelf Structure of Subtidal Currents in April to May 2001}

Figure 2 presents the low-pass-filtered current velocity as a function of depth and time at all sites (stations S2 - S7) along the ASIAEX mooring array. The measured currents along the array were rotated $20^{\circ}$ counterclockwise from east to follow the local isobaths. Thereafter, the along-shelf and cross-shelf components of the current velocity were positive toward the northeast and onshore across isobaths, respectively. Figure $2 \mathrm{a}$ presents the wind stress time series at $117^{\circ} \mathrm{E}, 20^{\circ} \mathrm{N}$ during the mooring deployment. The wind fluctuated quite frequently throughout the observation period (April - May 2001) when the northeast monsoon collapsed.

Table 1. Location, local water depth, observation depth (uppermost layer/lowest layer/vertical resolution), and record duration of each current velocity mooring. Stations with an asterisk are bottom-mounted moorings; others are subsurface moorings. An "R" preceding the depth values denotes the observation depth of Rotary Current Meter (RCM-8).

\begin{tabular}{|c|c|c|c|c|}
\hline Station & Mooring Location $\left({ }^{\circ} \mathbf{N},{ }^{\circ} \mathbf{E}\right)$ & Water Depth $(\mathbf{m})$ & Observation Depth (m) & Record Duration (Start time - End time) \\
\hline$* \mathbf{S} 2$ & $(22.18,117.06)$ & 71 & $8 / 64 / 4$ & 2001-04-21 13:00 - 2001-05-17 06:00 \\
\hline S3 & $(22.06,117.11)$ & 84 & $10.5 / 74.5 / 4$ & 2001-04-21 13:00 - 2001-05-05 04:00 \\
\hline S4 & $(21.90,117.18)$ & 120 & $18.5 / 98.5 / 4$ & 2001-04-21 13:00 - 2001-05-19 06:00 \\
\hline S5 & $(21.82,117.21)$ & 200 & $37 / 165 / 8$ & 2001-04-21 13:00 - 2001-05-18 08:00 \\
\hline S6 & $(21.72,117.24)$ & 275 & $30 / 220 / 10$ & 2001-04-21 13:00 - 2001-05-19 12:00 \\
\hline S7 & $(21.62,117.28)$ & 350 & $\begin{array}{c}10.4 / 94.5 / 4^{\mathrm{R}} 152,212,313 \\
10 / 90 / 5^{\mathrm{R}} 165,225,315 \\
30 / 220 / 10^{\mathrm{R}} 320 \\
15 / 95 / 5^{\mathrm{R}} 165,225,320 \\
\end{array}$ & $\begin{array}{l}2001-04-21 \text { 13:00 - 2001-05-18 23:00 } \\
2005-04-2905: 00 \text { - 2005-07-28 05:00 } \\
2005-07-28 \text { 11:00 - 2005-11-01 23:00 } \\
2005-11-0205: 00 \text { - 2006-01-18 11:00 }\end{array}$ \\
\hline$* \mathbf{H 1}$ & $(20.86,113.70)$ & 83 & $8 / 72 / 4$ & 2001-11-04 17:00 - 2002-03-21 05:00 \\
\hline
\end{tabular}


(a) QSCAT/NCEP blended wind stress

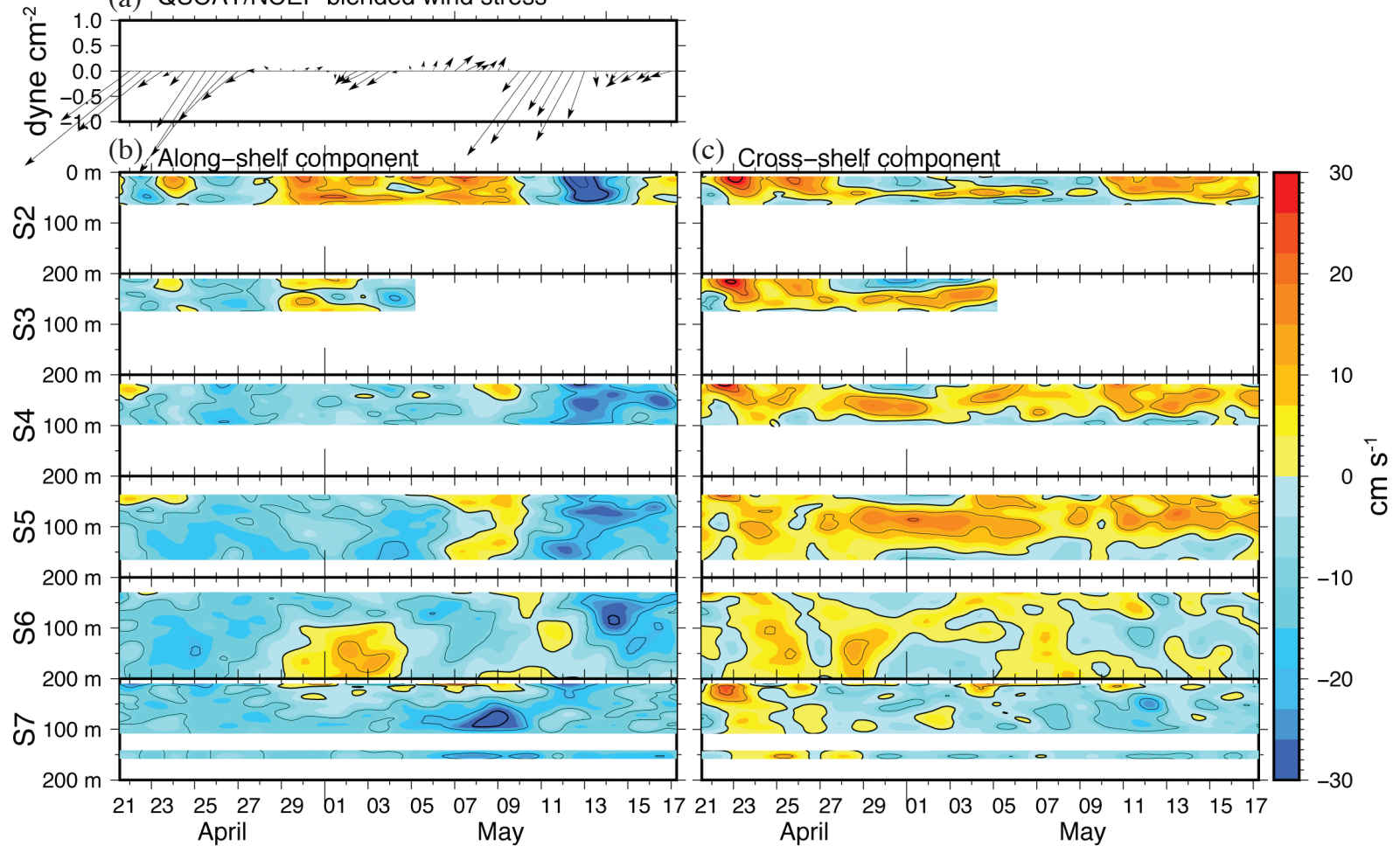

Fig. 2. (a) QSCAT/NCEP blended wind stress, (b) along-shelf subtidal currents, and (c) cross-shelf subtidal currents from the cross-shelf mooring array deployed in 2001 in ASIAEX. The contour line interval is $10 \mathrm{~cm} \mathrm{~s}^{-1}$. (Color online only)

However, the southwest monsoon did not begin to intensify (Hellerman and Rosenstein 1983). The wind was initially blowing toward the southwest, turning to the northeast, and finally rotating toward the southwest. The southwesterly winds were generally weaker than the northeasterly winds. The currents over the continental shelf and slope mostly flowed southwestward (Fig. 2b). The along-shelf currents were generally weak (approximately $20 \mathrm{~cm} \mathrm{~s}^{-1}$ ) and flowed mainly southwestward. The cross-shelf current velocity component (Fig. 2c) lacked a persistent orientation because the current shifted onshore and offshore back and forth across the isobaths. The maximum cross-shelf current speed reached $30 \mathrm{~cm} \mathrm{~s}^{-1}$ near the surface.

Two notable northeastward flow events were observed during the 1-month period of observations (i.e., from 29 April to 2 May 2001, and from 6 to 9 May 2001; Fig. 2b). During these two events, the northeast monsoon was weakened and winds shifted to the southwest. The maximum current speed reached approximately $30 \mathrm{~cm} \mathrm{~s}^{-1}$ near the surface at station $\mathrm{S} 2$, and the current speed gradually decreased in magnitude with increasing depth and offshore. However, the spatial structures of these two events varied. In the first event, the northeastward flow was confined to the shelf between stations S2 and S3 with a cross-shelf width of $15 \mathrm{~km}$. In the second event, nearly the entire shelf and slope was covered. The cross-shelf scale of this event was approximately $60 \mathrm{~km}$.
This difference might be attributable to the varying strengths of the wind forcing between the two events. Because the southwesterly wind was markedly stronger during the second event, the Ekman transport for the eastward component of the flow was larger. The shelf-wide response to the Ekman transport is discussed in section 4 .

\subsection{Variability of Currents at the Slope and on the Shelf}

Figure 3 presents the wind stress and $U$ (positive to the east) and $\mathrm{V}$ (positive to the north) components of current velocity at continental slope station S7 from May 2005 to January 2006. Summer-like (May - October) and winterlike (November - April) monsoon conditions were apparent (Fig. 3a). The monsoon winds were weak and generally directed toward the northeast during summer. The monsoon winds transition occurred from August to September, followed by strong and generally northeasterly winds during winter. The current fluctuated significantly during this transition period. After October, the northeast monsoon intensified and the current mainly reversed between westward and eastward. Two northeastward current events associated with the weakening of the northeasterly monsoon wind were observed from 3 to 15 November 2005, and from 24 to 27 December 2005.

A detailed observation of the subtidal currents may 


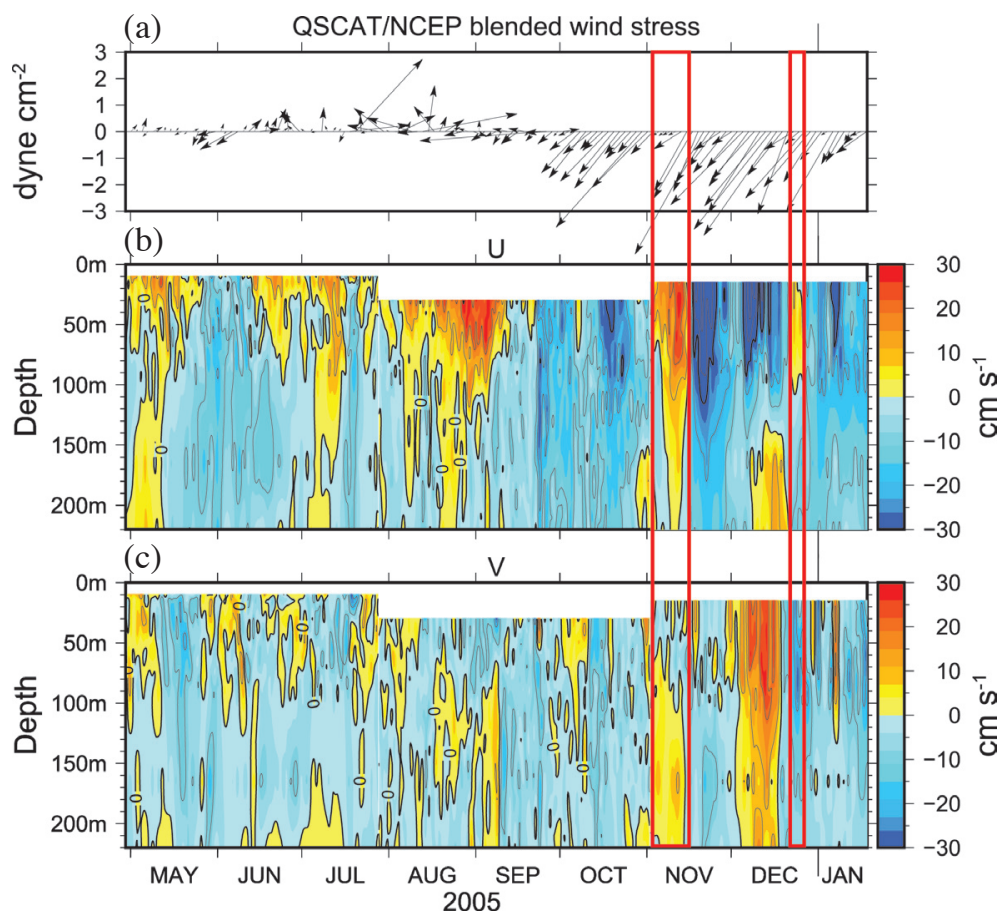

Fig. 3. (a) QSCAT/NCEP blended wind stress, (b) U component, and (c) V component of the subtidal current at station S7. The contour line interval is $10 \mathrm{~cm} \mathrm{~s}^{-1}$. Red boxes denote two northeastward current events associated with northeasterly monsoon wind weakening from 3 to 15 November 2005, and from 24 to 27 December 2005. (Color online only)

reveal that the current exhibits rotation-like variations. The currents at station S7 were depth averaged to clarify the characteristics of the current variation over the continental slope (Fig. 4a). Seasonal shifts in current variability were observed. From May to mid-September, the currents alternated between clockwise and counterclockwise rotations. This change in rotation reflected a pair of anticyclonic and cyclonic circulations on the slope. For example, from May to July, the current was initially northeastward and subsequently became southeastward, southwestward, and northwestward. The clockwise rotation ended in mid-June. The current subsequently rotated counterclockwise until mid-July and reversed until mid-September. From mid-September through winter, the flow shifted mainly between a southwestward and northeastward flow without long rotation duration. The monthly cyclonic and anticyclonic rotations suggest the importance of large eddies from the central basin of the SCS affecting the slope flow. The relationship between the current variability and eddies is discussed in section 4.1.

The shelf currents during winter at station $\mathrm{H} 1$ are presented in Fig. 5. The QSCAT/NCEP time series blended wind velocity at $113^{\circ} \mathrm{E}, 20^{\circ} \mathrm{N}$ demonstrates that the northeast monsoon prevailed throughout the entire winter (Fig. 5a). The wind was strong in November and December and slightly weakened in the following months. The wind occasionally weakened for several days, with the wind stress decreasing to $\leq 0.5$ dyne $\mathrm{cm}^{-2}$. Both the $\mathrm{U}$ and $\mathrm{V}$ components of the current velocity changed directions through- out the entire observational period. The currents over the continental shelf did not flow against the wind when strong northeast monsoon winds prevailed. Similar to the model results obtained by Chiang et al. (2008), on the shelf, the northeastward currents (i.e., the SCSWC) appeared after the northeasterly wind weakened. Each northeastward flow event lasted for 2 - 8 days, with speeds reaching $30 \mathrm{~cm} \mathrm{~s}^{-1}$ near the surface. The following three events were particularly notable. The northeasterly wind was strong during period 1 (5 - 15 November 2001), and the current primarily flowed southwestward. During period 2 (11 - 18 January 2002), the wind was relatively weak and the current was northeastward. In period 3 (15 - 25 February 2002), the wind was highly variable and a northeastward current appeared after the northeasterly wind weakened.

The scatter plots of the along-shelf wind stress and current velocity at station $\mathrm{H} 1$ clearly indicate that the current velocity direction correlates with the wind strength (Fig. 6). When the wind was strong (wind stress $>1$ dyne $\mathrm{cm}^{-2}$ ), the flow was mainly southwestward. The maximum southwestward flow speed reached $40 \mathrm{~cm} \mathrm{~s}^{-1}$ at the surface, decreasing with depth. When the wind weakened, the northeastward shelf flow emerged. During this time, the northeastward flow reached $30 \mathrm{~cm} \mathrm{~s}^{-1}$ near the surface. Monsoon winds play a crucial role in driving shelf currents during winter. The coefficients of determination $\left(\mathrm{R}^{2}\right)$ at $95 \%$ confidence intervals at three selected depths $(8,44$, and $72 \mathrm{~m})$ have similar values (approximately 0.5 ), indicating consistency 

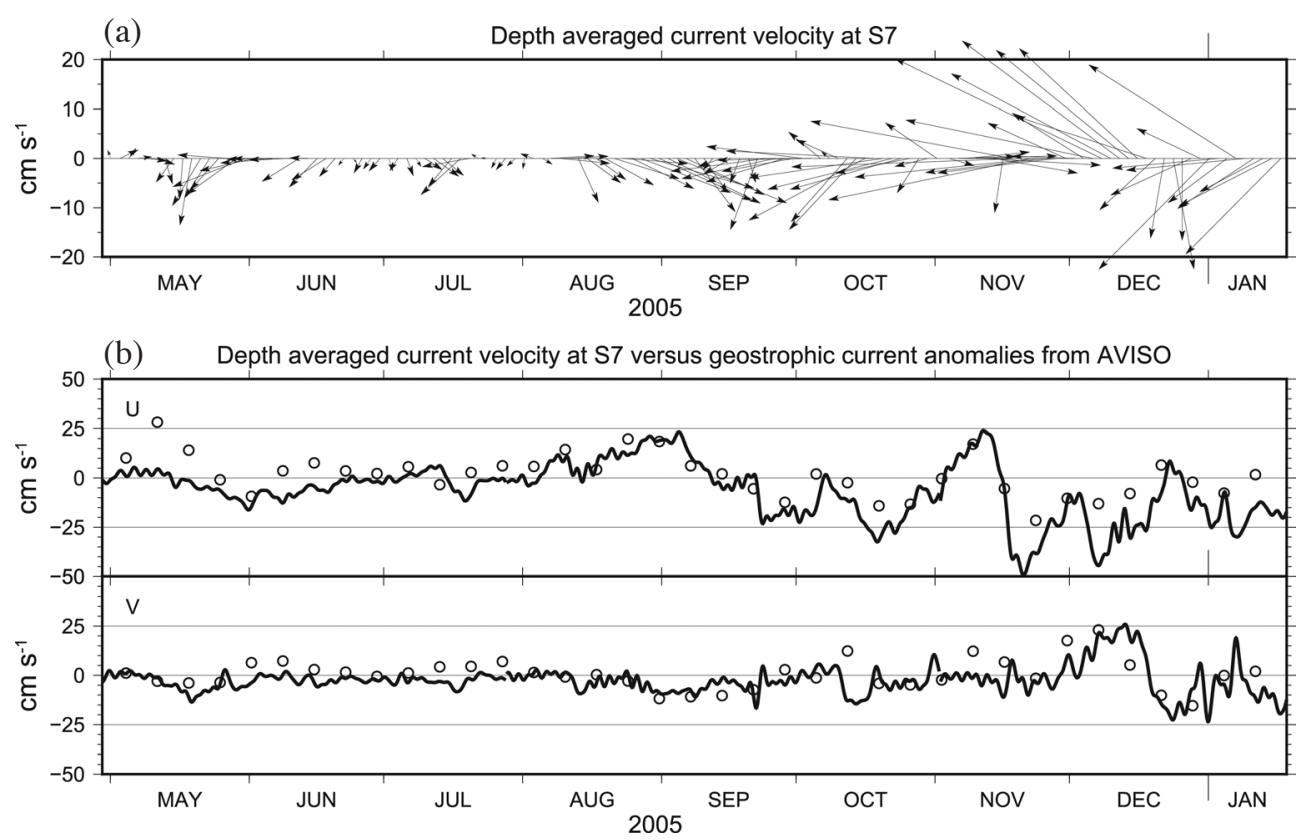

Fig. 4. Time series of (a) depth-averaged sub-tidal current velocity vectors at station S7, and (b) the U and V components of current velocity from (a) (solid lines) and the AVISO geostrophic current (empty circles).

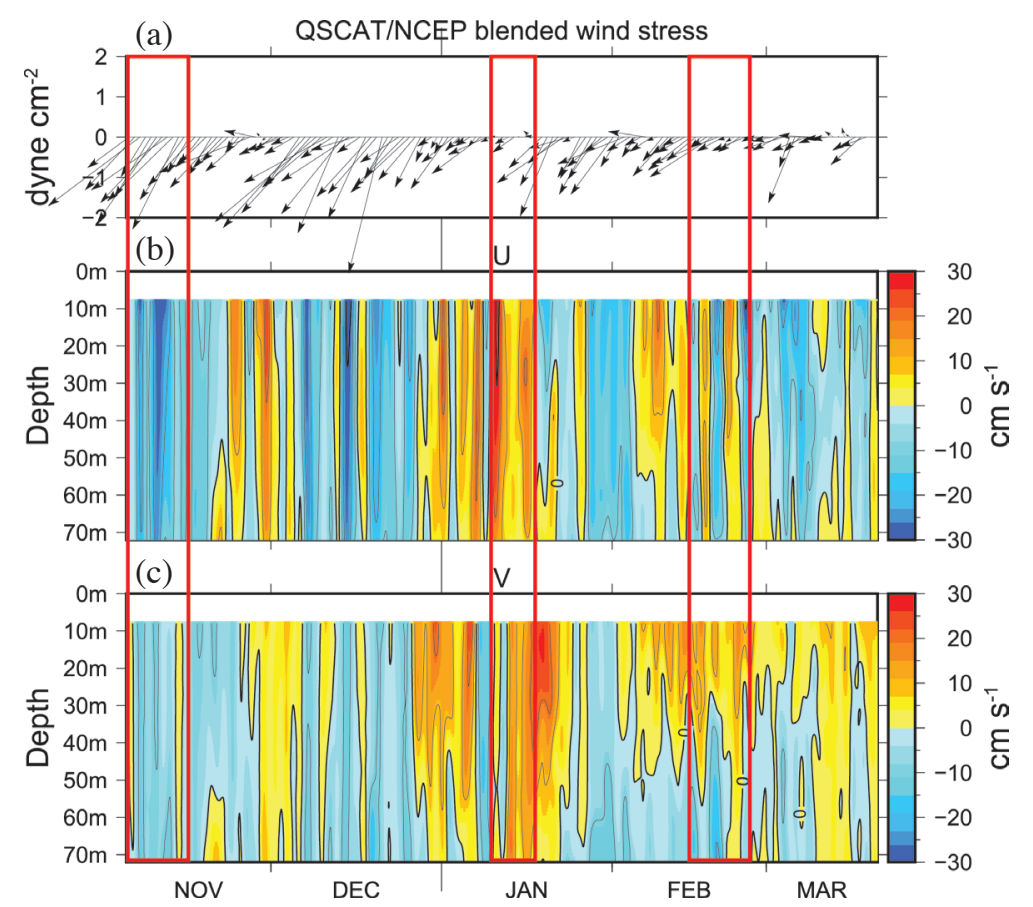

Fig. 5. (a) QSCAT/NCEP blended wind stress, (b) U component, and (c) V component of the subtidal current at station H1. The contour line interval is $10 \mathrm{~cm} \mathrm{~s}^{-1}$. Red boxes denote periods of three events that illustrate the relationship between winds and currents (see section 3.2 for details). (Color online only) 

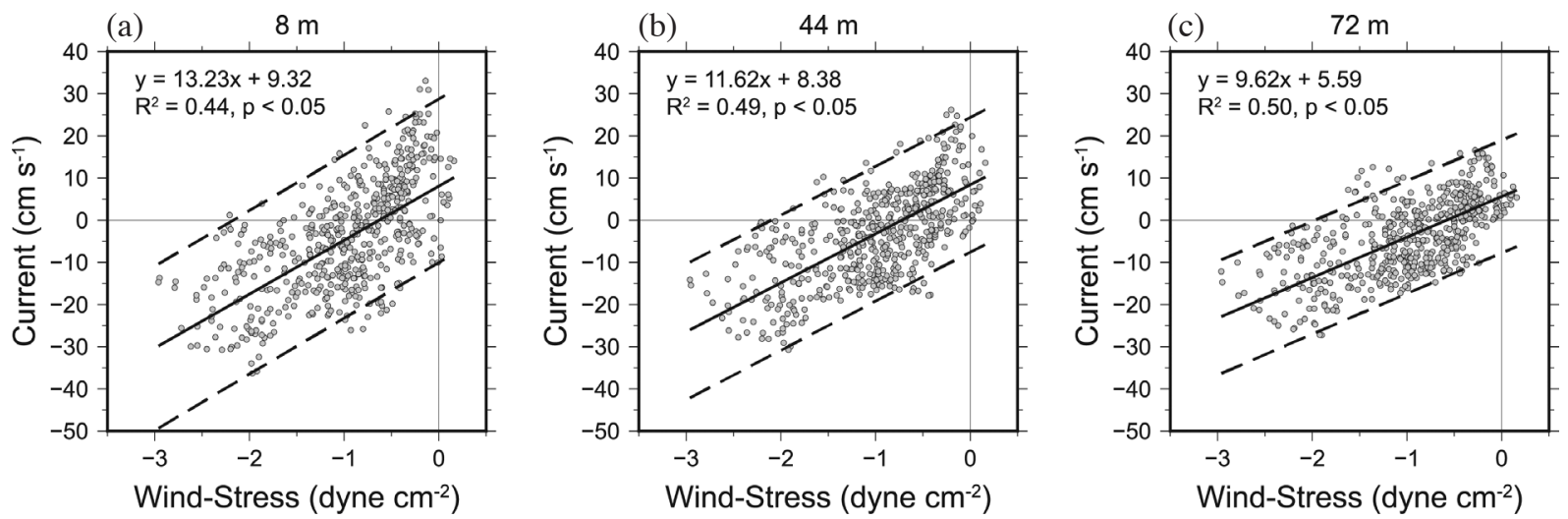

Fig. 6. Scatter plot of the along-shelf wind stress and 12-h lagged along-shelf currents at (a) $8 \mathrm{~m}$, (b) $44 \mathrm{~m}$, and (c) $72 \mathrm{~m}$ from station H1. The black line denotes the linear regression line between the winds and currents. The equations of linear fit and the coefficients of determination $\left(\mathrm{R}^{2}\right)$ at $95 \%$ confidence intervals are provided in each panel.

at depths. However, this result only explained $50 \%$ of the total variance; moreover, for a given wind stress, the uncertainty in current velocity predicted by a simple linear regression is about $\pm 15 \mathrm{~cm} \mathrm{~s}^{-1}$ with $95 \%$ prediction intervals. This implies that the current may be controlled by other factors in addition to the local wind forcing.

The aforementioned findings indicate that the currents measured at the slope and on the shelf vary considerably. The factors that may affect the variations in the currents at the slope and on the shelf are discussed in section 4.

\section{DISCUSSION}

\subsection{Eddy Effect on the Slope Currents}

The currents over the continental slope of the northern SCS (station S7 in 2005 and 2006) are described in section 3.2. The observed sub-tidal currents exhibited a seasonally varying rotating feature and may be related to the presence of eddies. To examine the effect of eddies on the slope current variability, the depth-averaged currents were compared with the satellite-derived geostrophic current, which was derived from the weekly altimeter SSHA extracted from Archiving, Validation and Interpretation of Satellite Oceanographic data (AVISO, available at http://www.aviso.altimetry.fr/duacs/). Figure $4 \mathrm{~b}$ presents the comparison between the depth-averaged current (solid lines) and geostrophic current anomaly (empty circles). The satellite-derived geostrophic current was consistent with the observed current, indicating that currents on the slope correlate highly with sea level changes and are in geostrophic balance. Analyzing the relationship between the observed current and SSHA in a planned view is therefore necessary. Note that the moored data were 48-h low-pass-filtered and the weekly satellite altimetry data is able to resolve motions with a temporal scale $>20$ days and spatial scale $>70-100 \mathrm{~km}$. The strong correlation was based on mesoscale $(50-300 \mathrm{~km})$ and large- scale (> $300 \mathrm{~km}$ ) dynamic fields (Sudre and Morrow 2008). Figure 7 presents the eddy impact evolution on the slope current during the summer (left panel) and winter (right panel). The slope currents were affected by different types of eddies in different seasons. In summer, the slope currents were affected by the anticyclonic or cyclonic eddy pair, which originated in the west Luzon Strait and propagated west or southwestward along the continental slope. The size of the eddy was approximately $1^{\circ}$ in latitude and $110 \mathrm{~km}$ in diameter. From 24 August to 7 September (Fig. 7a), the slope currents varied with the passage of the eddy. The slope currents first flowed northeastward when the anticyclonic eddy was located southeast of station S7, and subsequently turned southwestward as the cyclonic eddy approached the mooring. In winter, the large-scale eddy west of the Luzon Strait affected the slope current (Fig. 7b). On 28 December 2005, a large-scale eddy appeared to the west of Luzon Island. In the following days, as the eddy grew and expanded toward the slope, the currents became stronger.

\subsection{Wind Effect on the Shelf Currents}

The shelf currents were studied through analyzing the moored current velocity observed throughout an entire winter (section 3.2). Wind forcing plays a crucial role in driving subtidal currents on the shelf, but the shelf current responses to wind forcing remain unclear. Further analysis of the observations is warranted to elucidate their characteristics.

A typical wind forcing activity is observed in water mass transports (i.e., Ekman transport). In the Northern Hemisphere, Ekman transports are directed toward the right of the wind. Therefore, an along-shelf wind drives shelf water toward or away from the coast. Because the sea level at the coast may rise or fall because of Ekman transport, a sea level gradient may appear across the shelf, resulting in a geostrophic along-shelf current. 
According to Ekman theory, a surface Ekman current is embedded in a geostrophic current (Pedlosky 1986; Cushman-Roisin 1994). To separate geostrophic and Ekman currents from the observed velocity, a reference layer (the bottom of the Ekman layer) should therefore be chosen. The seawater temperature, salinity, and density profiles at station H1 (Fig. 8) indicate that the shelf water is well mixed in the upper 60-m layer. The thermocline was between 60 and $70 \mathrm{~m}$ deep. The base of the surface Ekman layer can therefore be located at a depth of $70 \mathrm{~m}$. Theoretically, the bottom boundary layer thickness can be estimated using $\sqrt{2 v / f}$ (Cushman-Roisin 1994), where $v$ is the kinematic viscosity and $f$ is the Coriolis parameter. In an area in the ocean where the averaged tidal current at the bottom is $10 \mathrm{~cm} \mathrm{~s}^{-1}$ (a)

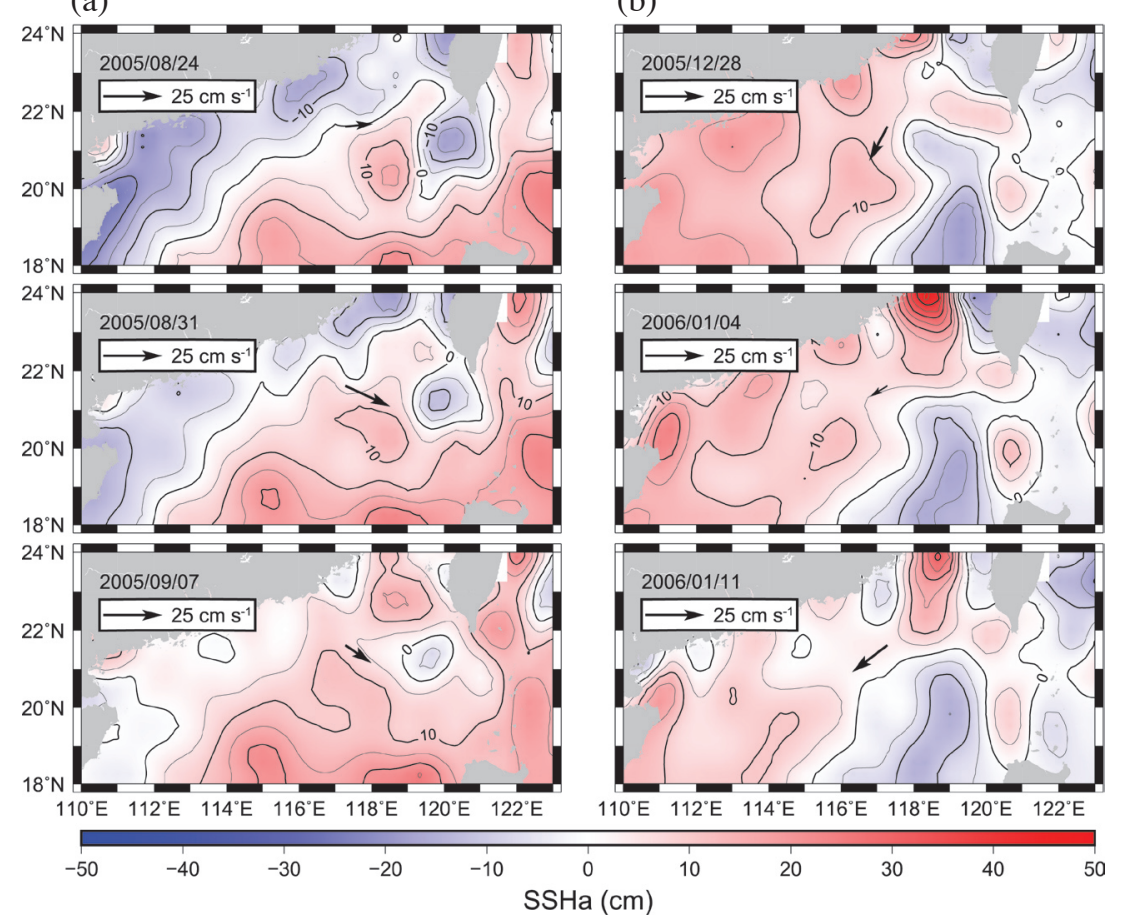

Fig. 7. Plan view of SSHAs in (a) summer (from 24 August to 7 September 2005) and (b) winter (from 28 December 2005 to 11 January 2006). The contours denote SSHAs. The contour interval is $5 \mathrm{~cm}$. The arrows denote the depth-averaged subtidal current from Fig. 4. (Color online only)

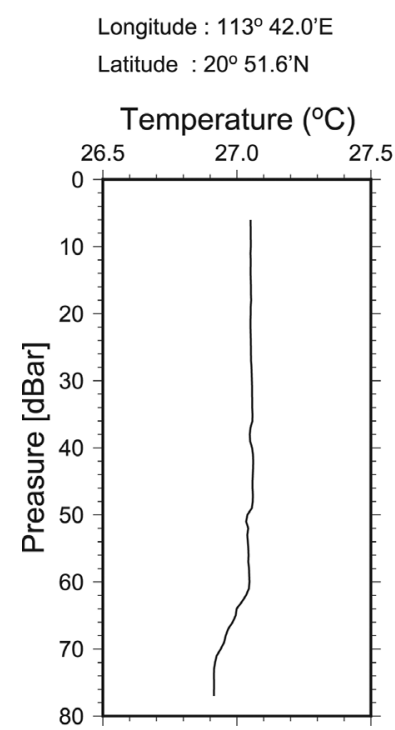

SBE9/11 CTD cast

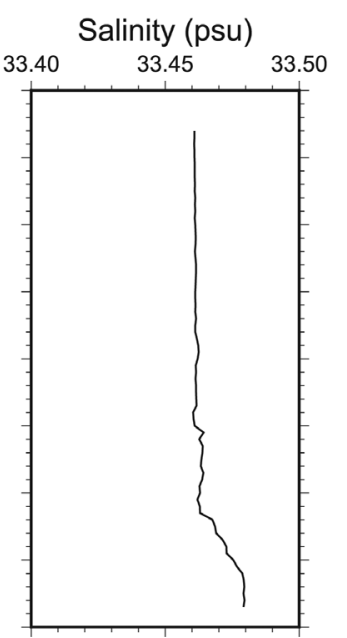

Station : H1

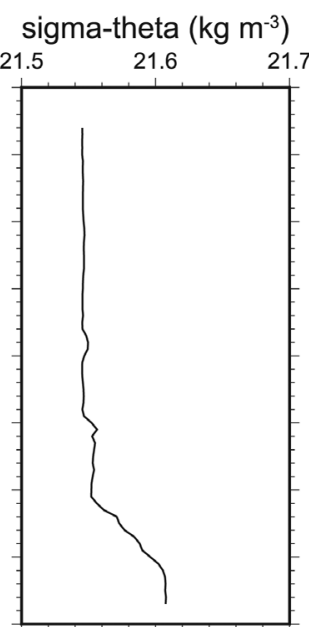

Fig. 8. Temperature (left panel), salinity (middle panel), and density (right panel) profiles at station H1. Conductivity, temperature, and depth were sampled as the ADCP mooring was deployed. 
(not shown), the appropriate value of $v$ would be $30 \mathrm{~cm}^{2} \mathrm{~s}^{-1}$ (Gill 1982). The bottom boundary layer thickness at station $\mathrm{H} 1$ would be approximately $10 \mathrm{~m}$. We selected $72 \mathrm{~m}(11 \mathrm{~m}$ above the bottom) as the reference layer where the current is in geostrophic balance. The selected reference layer was above the boundary layer, and hence, the frictional effects from the bottom should not have a significant effect on the geostrophic current.

To further examine the geostrophic balance of the current at $72 \mathrm{~m}$, we compared it with the geostrophic current estimated from the sea level anomaly difference between Hong Kong and station H1. Sea-level data at Hong Kong and station $\mathrm{H} 1$ were obtained from the Joint Archive for Sea Level, University of Hawaii Sea Level Center (http:// ilikai.soest.hawaii.edu/uhslc/data.html) and from a moored pressure gauge, respectively. Figure 9, from top to bottom, presents the along-shelf wind stress, sea level anomalies, and the along-shelf components of the current velocity recorded at station H1. All parameters were 48-h low-pass-filtered. The sea level anomalies were consistent with the along-shelf winds. A sea level set up was observed when the northeasterly winds were strong. The sea level anomaly trend in Hong Kong was almost coincident with that at station H1. This finding implies that shelf waters are transported in the same direction across the shelf. The sea level setup or set down would generate a pressure gradient across the shelf, and an along-shelf geostrophic current would develop. The alongshelf current velocity component at $72 \mathrm{~m}$ and the geostrophic current estimated from the sea level anomaly difference be- tween the Hong Kong and H1 stations were quite similar (Fig. 9c). The variability of the along-shelf moored currents was consistent with that of the geostrophic current resulting from the large-scale setup or set down across the shelf.

The wind-driven Ekman current for each vertical bin was then obtained from the measured current by subtracting the current velocity at $72 \mathrm{~m}$ (i.e., the geostrophic component). The progressive vector diagram (PVD) of winddriven Ekman currents at six selected depths is shown in Fig. 10. Surface wind stress is plotted along the PVD at $8 \mathrm{~m}$. The currents were generally flowing to the right of the winds. Some head-wind currents appeared at $8 \mathrm{~m}$ during the observation, which was probably due to the varying current direction at depth relative to that at the surface or the weak wind forcing as demonstrated in Fig. 6. The current veered clockwise and decreased in amplitude with depth. These properties are consistent with Ekman theory in the Northern Hemisphere, although the angle between winds and currents occasionally exceeds $90^{\circ}$; this result was also demonstrated by Chereskin (1995) for the Ekman balance in the California Current and was discussed by Price et al. (1987). Consequently, the sea level at the coast should be set up based on the Ekman transport when northeasterly monsoon wind prevails and vice versa.

A spectral analysis was performed to quantify the relationship between the Ekman transport and sea level at the coast (i.e., Hong Kong). Figure 11 presents the energy-preserved spectrum of Ekman transport strength and the coherence spectrum between the cross-shelf Ekman transport and
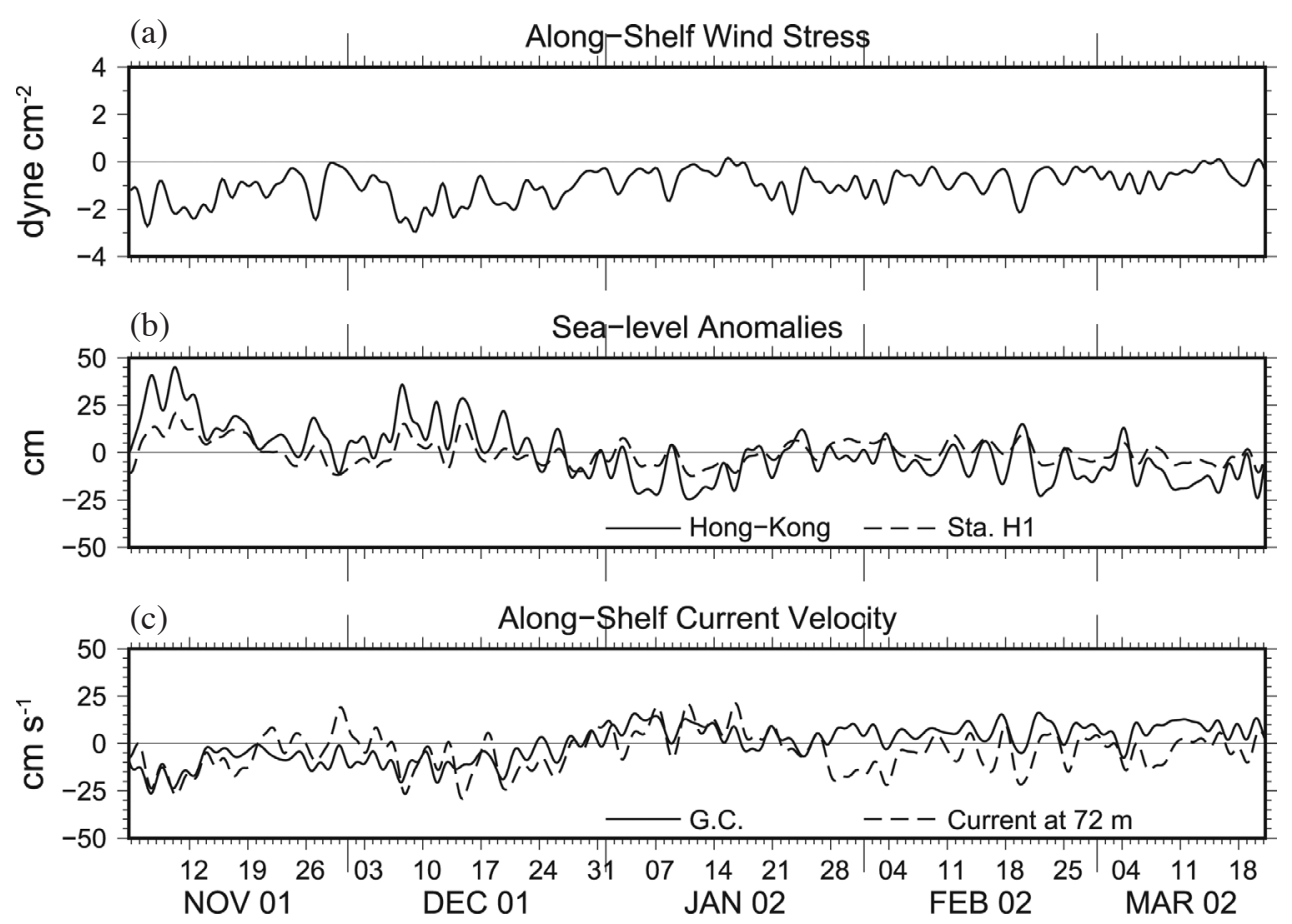

Fig. 9. Time series of (a) along-shelf component of wind stress, (b) sea level anomalies at the Hong-Kong and H1 stations, and (c) geostrophic current (G.C.) and along-shelf current at $72 \mathrm{~m}$. All parameters were 48-h low-pass-filtered. 


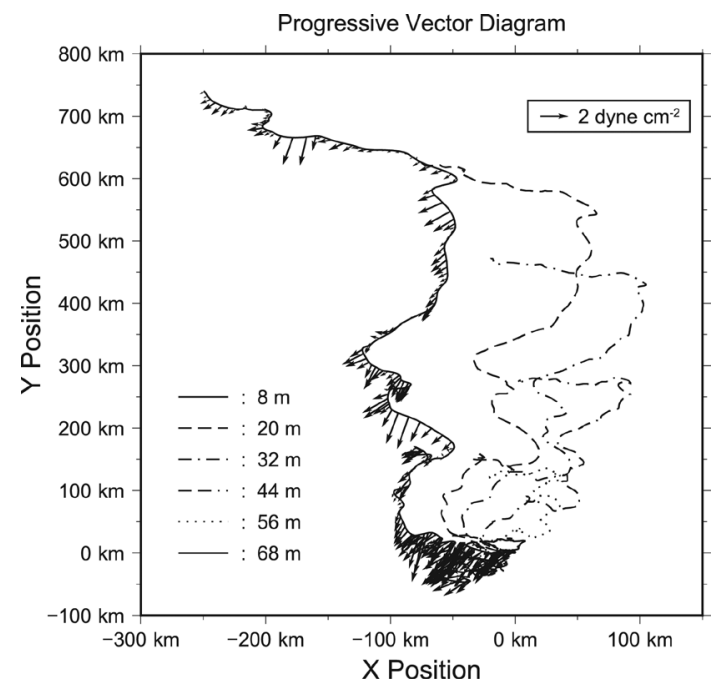

Fig. 10. PVD of Ekman currents at six selected depths. The wind stress was plotted along with the PVD at $8 \mathrm{~m}$.
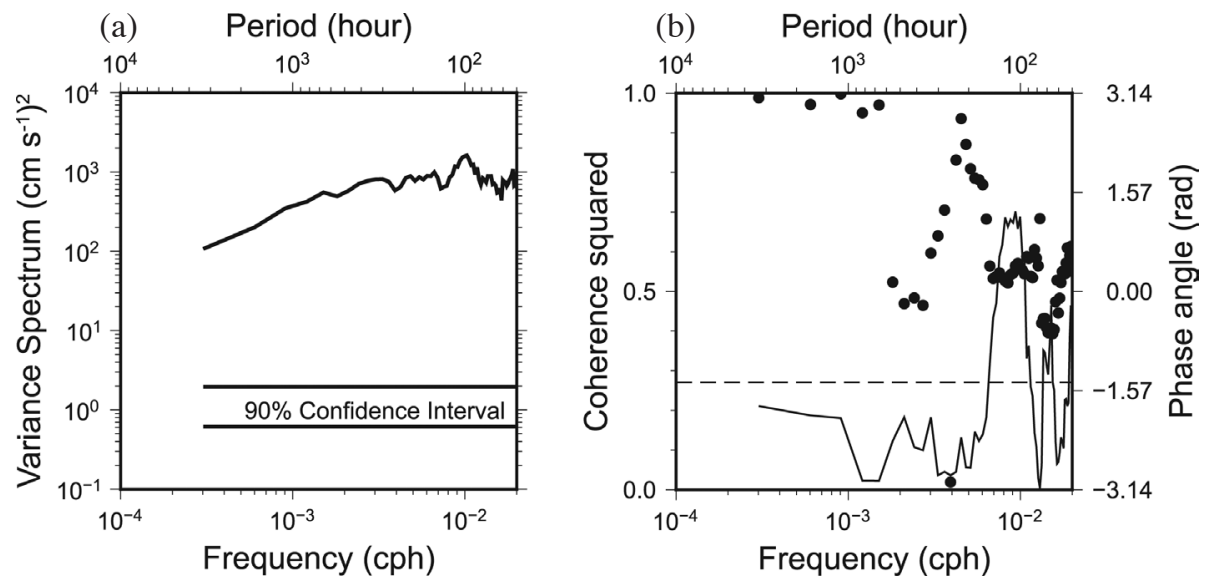

Fig. 11. (a) Energy-preserved spectrum of the Ekman transport. The 90\% confidence interval is also shown. (b) The coherence squared (solid lines) and phases (filled circles) between the cross-shelf component of the Ekman transport and sea level at Hong-Kong. The dashed line denotes the 90\% confidence interval.

sea level component in Hong Kong. The Ekman transport was simply estimated by integrating the Ekman currents throughout the depth bins, as shown in Fig. 10. The energypreserved Ekman transport strength spectrum (Fig. 11a) revealed a significant energy peak near the 100 -h period, indicating a volume transport time scale on the shelf in response to wind forcing. The coherence between the along-shelf Ekman transport and sea level component in Hong Kong exhibited a high correlation (approximately 0.7 ) in the time range of approximately $100 \mathrm{~h}$. This finding implies that the 100-h sea level variation in Hong Kong was affected by the winddriven Ekman cross-shelf transport. However, the phase lag indicated that the sea level led the cross-shelf Ekman transport by approximately $6 \mathrm{~h}$, which may be attributable to two reasons. Because the sea level in Hong Kong is located at the coast, the sea level response to the wind may be faster than that in deep water because of the continental boundary effect. Another reason is the delay in the weather system arrival time at station $\mathrm{H} 1$ because cold winter storms usually move from north to south in the area.

The along-shelf geostrophic current (i.e., observed current at $72 \mathrm{~m}$ ) demonstrated two significant energy peaks near the 100- and 400-h periods (Fig. 12a). The 100-h period variation can be related to the sea level variation across the shelf attributed to the Ekman transport, as discussed previously. Because the Ekman transport strength energy preserved spectrum displays a significant energy peak only at $100 \mathrm{~h}$, the 400-h period variation could result from another driving force. Chao et al. (1995) and Chiang et al. (2008) suggested that the pressure gradient between Hainan Island and the southern opening of the Taiwan Strait is a driving force for the along-shelf currents. Therefore, the 400-h 

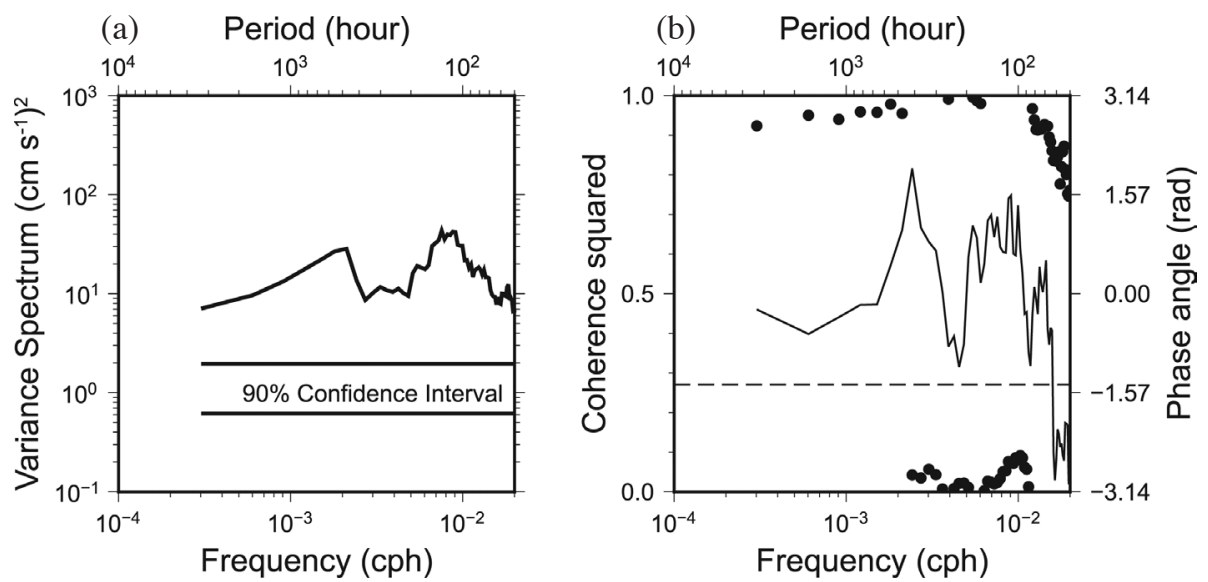

Fig. 12. (a) Energy-preserved spectrum of the along-shelf geostrophic current (i.e., the observed current at $72 \mathrm{~m}$ ). The $90 \%$ confidence interval is also shown. (b) The coherence squared (solid lines) and phases (filled circles) between the along-shelf current and sea level near Hainan Island. The dashed line denotes the $90 \%$ confidence interval. The sea surface elevation data at Hainan Island was extracted from the output of the HYbrid Coordinate Ocean Model (HYCOM, https://hycom.org/data/glbu0pt08/).

period current variation may be attributable to this mechanism. The inference can be validated by calculating the coherence spectrum between the along-shelf current and sea level near Hainan Island. Because no observational sea level data were available during our study at Hainan Island, the modeled sea level output from HYbrid Coordinate Ocean Model (HYCOM, https://hycom.org/data/glbu0pt08/) was used. The data resolution has a $3-\mathrm{h}$ duration and $1 / 12^{\circ}$ horizontal resolution. Comparisons between the modeled sea level anomalies showed consistency with observational sea levels in Hong Kong and station H1 (not shown). Figure $12 \mathrm{~b}$ presents the coherence spectrum and the phases between the along-shelf current and sea level near Hainan Island $\left(19.36^{\circ} \mathrm{N}, 111.36^{\circ} \mathrm{E}\right)$. The current and sea level were highly correlated near the 100 - and 400 -h periods, respectively. The phases display the current led sea levels of approximately $50 \mathrm{~h}$ in the 100 -h period variation and $180 \mathrm{~h}$ in the 400 -h variation, indicating that the sea level at Hainan Island leads the along-shelf current variation.

Consequently, subtidal currents on the shelf include two major components: the Ekman current, as a result of wind forcing, and the along-shelf geostrophic current, as a result of sea level variations. The Ekman transport caused the sea level variation at the coast in the 100 -h period and hence the cross-shelf sea level gradient variation. One of the along-shelf currents reflects the 100 -h period variation. The other along-shelf current variation in the 400-h period is due to the along-shelf sea level gradient, as suggested by Chao et al. (1995) and Chiang et al. (2008).

\subsection{Water Runoff Effect from the Taiwan Strait Induced by Typhoons}

Circulation on the continental shelf of the northern
SCS is affected by many factors. In addition to the monsoon wind changes effect (e.g., Wyrtki 1961; Nitani 1972; Wang and Chern 1987a, b), Kuroshio intrusion (e.g., Shaw 1991, 1994), and mesoscale eddies (e.g., Li et al. 1988; Gawarkiewicz et al. 2004), the river runoff from the Taiwan Strait induced by typhoons plays a crucial role in driving shelf currents (Zhang et al. 2009; Chang et al. 2010). For example, Zhang et al. (2009) observed a strong southward transport in the Taiwan Strait driven by typhoon-generated local wind stress and the along-strait sea level gradient. Because the southward flow entered the shelf region, currents were presumably affected concurrently.

The current at station S7 intensified with flow to the southeast at the end of August 2005 to early September 2005 , and this phenomenon lasted for a few days. This phenomenon may be attributable to the strong runoff from Taiwan Strait because of the passage of a Category- 5 typhoon, Talim, during this period. For example, Zhang et al. (2009) numerically studied the evolution of the depth-averaged current when Typhoon Talim crossed the Taiwan Strait. The current from the Taiwan Strait initially flowed southwestward and then shifted toward the southeast when the flow was far from the strait (Fig. 11a). Because station S7 was located in the area of the southeastward flow, the currents were likely affected by the runoff flow and shifted to flow toward the southwest. However, additional studies are required to investigate the runoff effects from the Taiwan Strait on shelf and slope circulation.

\section{SUMMARY}

In the past decade, international science programs (ASIAEX pilot study in 2000, ASIAEX in 2001, and VANS/ WISE in 2005 and 2006) have been conducted to study the 
evolution of the internal solitary wave field and current velocity across the shelf break in the northern SCS. Moored ADCPs were distributed over the continental shelf for observation programs lasting 20 days or more. These ADCPs facilitated the study of the spatial and temporal variability in subtidal (48-h low-pass-filtered) currents over the shelf and slope regions.

Subtidal currents across the shelf did not show a consistent pattern. The shelf current did not oppose the wind when strong northeasterly monsoon winds prevailed. The northeastward flow appeared only when the northeasterly winds weakened (i.e., wind stress $<1$ dyne $\mathrm{cm}^{-2}$ ), implying that winds play a crucial role in forcing shelf currents.

The observed subtidal currents on the shelf comprise two components: the Ekman current and the geostrophic current. The cross-shelf component of the depth-integrated Ekman current exhibited a high correlation with the 100-h sea level variation in Hong Kong, indicating variation in the cross-shelf sea level gradient induced by the Ekman transport. The sea level set up at the coast when the northeasterly wind was strong and vice versa. The variation in the cross-shelf sea level gradient further contributed to the along-shelf geostrophic current during this period. In addition to the 100-h variations, an along-shelf geostrophic current variation of $400 \mathrm{~h}$ was observed, which resulted from the along-shelf sea level gradients.

Shelf and slope currents are affected by many factors. Typhoon runoff water from the Taiwan Strait and eddies in the central basin of the northern SCS play a role in forcing current variability. Eddies affect slope currents in various ways. During summer, currents are affected by a mesoscale eddy originating in the west of the Luzon Strait and in a pair of cyclone/anticyclone counter-rotating eddies; during winter, currents are affected by the large-scale cyclonic circulation in the west of Luzon Island. Additional observational studies are warranted to fully understand the current variability over the continental shelf and slope in the northern SCS.

Acknowledgements Kai-Chieh Yang shared equally correspondence in preparation of this manuscript. We are grateful to Prof. Tswen-Yung Tang for his support and for providing mooring data, to Prof. Joe Wang from National Taiwan University for sharing his expertise to improve this manuscript, and to Dr. Timothy Duda from Woods Hole Oceanographic Institution for his comments on the manuscript. In addition, we thank Mr. Wen-Hwa Her from National Taiwan University for his efforts on mooring deployment/recovery and the crews of R/V Ocean Researcher I, II, and III for their assistance with the fieldwork. The altimeter products used in this study were produced by Ssalto/Duacs and distributed by AVISO, with support from CNES (http://www.aviso. altimetry.fr/duacs/). Glen Gawarkiewicz was supported by the Office of Naval Research of the United States (N0001412-1-0325).

\section{REFERENCES}

Bao, X, Y. Hou, C. Chen, F. Chen, and M. Shi, 2005: Analysis of characteristics and mechanism of current system on the west coast of Guangdong of China in summer. Acta. Oceanol. Sin., 24, 1-9.

Beardsley, R. C., T. F. Duda, J. F. Lynch, J. D. Irish, S. R. Ramp, C. S. Chiu, T. Y. Tang, Y. J. Yang, and G. Fang, 2004: Barotropic tide in the northeast South China Sea. IEEE J. Ocean. Eng., 29, 1075-1086, doi: 10.1109/ JOE.2004.833226. [Link]

Chang, Y. C., R. S. Tseng, and L. R. Centurioni, 2010: Typhoon-induced strong surface flows in the Taiwan Strait and Pacific. J. Oceanogr., 66, 175-182, doi: 10.1007/s10872-010-0015-y. [Link]

Chao, S. Y., P. T. Shaw, and J. Wang, 1995: Wind relaxation as possible cause of the South China Sea Warm Current. J. Oceanogr., 51, 111-132, doi: 10.1007/ BF02235940. [Link]

Chereskin, T. K., 1995: Direct evidence for an Ekman balance in the California Current. J. Geophys. Res., 100, 18261-18269, doi: 10.1029/95jc02182. [Link]

Chiang, T. L., C. R. Wu, and S. Y. Chao, 2008: Physical and geographical origins of the South China Sea Warm Current. J. Geophys. Res., 113, C08028, doi: 10.1029/2008JC004794. [Link]

Cushman-Roisin, B., 1994: Introduction to Geophysical Fluid Dynamics, Prentice Hall, Englewood Cliffs, New Jersey, 320 pp.

Duda, T. F., J. F. Lynch, J. D. Irish, R. C. Beardsley, S. R. Ramp, C. S. Chiu, T. Y. Tang, and Y. J. Yang, 2004: Internal tide and nonlinear internal wave behavior at the continental slope in the northern South China Sea. IEEE J. Ocean. Eng., 29, 1105-1130, doi: 10.1109/ JOE.2004.836998. [Link]

Gan, J., L. Li, D. Wang, and X. Guo, 2009: Interaction of a river plume with coastal upwelling in the northeastern South China Sea. Cont. Shelf Res., 29, 728-740, doi: 10.1016/j.csr.2008.12.002. [Link]

Gawarkiewicz, G., J. Wang, M. Caruso, S. R. Ramp, K. H. Brink, and F. Bahr, 2004: Shelf break circulation and thermocline structure in the northern South China Sea - Contrasting spring conditions in 2000 and 2001. IEEE J. Ocean. Eng., 29, 1131-1143, doi: 10.1109/ JOE.2004.839123. [Link]

Gill, A. E., 1982: Atmosphere-Ocean Dynamics, Academic Press, Orlando, Florida, 662 pp.

Guan, B. X., 1978: The warm current in the South China Sea - a current flowing against the wind in winter in the open sea off Guangdong Province. Oceanol. et Limnol. Sinica, 9, 117-127. (in Chinese)

Guan, B. X., 1985: Some temporal and spatial distribution features of the wintertime counter-wind current in the northern South China Sea. Oceanol. et Limnol. Sinica, 
16, 429-437. (in Chinese)

Guan, B. X. and S. J. Chen, 1964: The current systems in the near-sea area of China seas, $85 \mathrm{pp}$. (in Chinese)

Guan, B. X. and G. Fang, 2006: Winter counter-wind currents off the Southeastern China coast: A review. $J$. Oceanogr., 62, 1-24, doi: 10.1007/s10872-006-0028-8. [Link]

Guo, Z. X., T. H. Yang, and D. Z. Qiu, 1985: The South China Sea Warm Current and the SW-ward current on its right side in winter. J. Trop. Oceanogr., 4, 1-9. (in Chinese)

Hellerman, S. and M. Rosenstein, 1983: Normal monthly wind stress over the world ocean with error estimates. J. Phys. Oceanogr., 13, 1093-1104, doi: 10.1175/1520 -0485(1983)013<1093:NMWSOT>2.0.CO;2. [Link]

Hsueh, Y. and L. Zhong, 2004: A pressure-driven South China Sea Warm Current. J. Geophys. Res., 109, C09014, doi: 10.1029/2004JC002374. [Link]

Hu, J., H. Kawamura, H. Hong, and Y. Qi, 2000: A review on the currents in the South China Sea: Seasonal circulation, South China Sea Warm Current and Kuroshio intrusion. J. Oceanogr., 56, 607-624, doi: 10.1023/A:1011117531252. [Link]

Li, L., W. D. Nowlin, Jr. and J. L. Su, 1998: Anticyclonic rings from the Kuroshio in the South China Sea. DeepSea Res. Part I-Oceanogr. Res. Pap., 45, 1469-1482, doi: 10.1016/S0967-0637(98)00026-0. [Link]

Lynch, J. F., S. R. Ramp, C. S. Chiu, T. Y. Tang, Y. J. Yang, and J. A. Simmen, 2004: Research highlights from the Asian Seas International Acoustics Experiment in the South China Sea. IEEE J. Ocean. Eng., 29, 1067-1074, doi: 10.1109/joe.2005.843162. [Link]

Nitani, H., 1972: Beginning of the Kuroshio. In: Stommel, H. and K. Yoshida (Eds.), Kuroshio, Its Physical Aspects, University of Tokyo Press, Tokyo, 129-163.

Pedlosky, J., 1986: Geophysical Fluid Dynamics, $2^{\text {nd }}$ Edition, Berlin: Springer Verlag, doi: 10.1007/978-14684-0071-7. [Link]

Price, J. F., R. A. Weller, and R. R. Schudlich, 1987: Winddriven ocean currents and Ekman transport. Science,
238, 1534-1538, doi: 10.1126/science.238.4833.1534. [Link]

SCSB (South China Sea Branch, SOA), 1990: Report of Decadal Hydrographic Series Survey of the Shelf and Adjacent Waters of the Northern South China Sea, China Ocean Press, Beijing, 254 pp. (in Chinese)

Shaw, P. T., 1991: The seasonal variation of the intrusion of the Philippine Sea water into the South China Sea. J. Geophys. Res., 96, 821-827, doi: 10.1029/90jc02367. [Link]

Shaw, P. T. and S. Y. Chao, 1994: Surface circulation in the South China Sea. Deep-Sea Res. Part I-Oceanogr. Res. Pap., 41, 1663-1683, doi: 10.1016/09670637(94)90067-1. [Link]

Su, J. L. and W. Wang, 1987: On the sources of the Taiwan Warm Current from the South China Sea. Chin. J. Oceanol. Limnol., 5, 299-308, doi: 10.1007/ BF02843812. [Link]

Sudre, J. and R. A. Morrow, 2008: Global surface currents: a high-resolution product for investigating ocean dynamics. Ocean Dyn., 58, 101-118, doi: 10.1007/ s10236-008-0134-9. [Link]

Wang, J. and C. S. Chern, 1987a: The warm-core eddy in the northern South China Sea. I. Preliminary observations on the warm-core eddy. Acta Oceangr. Taiwanica, 18, 92-103.

Wang, J. and C. S. Chern, 1987b: The warm-core eddy in the northern South China Sea. II. A simple mechanism for the establishment and development of the warmcore eddy. Acta Oceanogr. Taiwanica, 18, 104-113.

Wyrtki, K., 1961: Physical oceanography of the Southeast Asian waters. Scripps Institute of Oceanography NAGA Report, vol. 2, 195 pp.

Yang, J., D. Wu, and X. Lin, 2008: On the dynamics of the South China Sea Warm Current. J. Geophys. Res., 113, C08003, doi: 10.1029/2007JC004427. [Link]

Zhang, W. Z., H. S. Hong, S. P. Shang, X. H. Yan, and F. Chai, 2009: Strong southward transport events due to typhoons in the Taiwan Strait. J. Geophys. Res., 114, C11013, doi: 10.1029/2009JC005372. [Link] 